\title{
PROVA CONTRÁRIA: RESTOS E CICATRIZES
}

\author{
Natasha Fernanda Ferreira Rocha
}

RESUMO: O período da ditadura militar brasileira foi um dos mais sombrios de nossa história oficial. Este artigo pretende analisar a obra Prova Contrária, do autor paulistano Fernando Bonassi, publicada em 2003, que tematiza, de alguma maneira, tal episódio histórico. A intenção é perceber como o trato literário é empregado na revisitação do fato. Para tanto, faremos um apanhado do que foi o período militar, além de apresentaremos algumas questões teóricas sobre o romance histórico contemporâneo e um panorama sobre a literatura pós-64 será traçado, a fim de compreender a obra de Fernando Bonassi inserido das prerrogativas que alicerçam esse subgênero e como ele sinaliza um conjunto subjetivo de restos e cicatrizes dos "anos de chumbo".

Palavras-chave: literatura brasileira contemporânea; ditadura militar; Fernando Bonassi.

I.

Você morre apenas uma morte. Mas a revolução morre várias mortes Mauser, Heiner Müller

O regime militar brasileiro foi um dos períodos mais sombrios de nossa história oficial. Instaurado pelo golpe que depôs o então presidente João Goulart, em abril de 1964, durou 25 anos. Não há ainda hoje, passados 50 anos do fato, consenso sobre as motivações que levaram à consolidação do regime totalitário. No cenário paranoico criado pela Guerra Fria e com um governo de esquerda em seu comando, o Brasil encontrava-se cortado por diferentes conflitos e linhas de força: pressões sociais, a alta da inflação, greves crescentes, a incompatibilidade do governo com os Estados Unidos uma das forças mobilizadoras do golpe, na figura de Lincoln Gordon, embaixador americano no Brasil - as mudanças de base defendidas por Jango, que atingiam interesses constituídos e desagradavam a classe média mais conservadora, formavam o cenário que propiciou bruscas e autoritárias intervenções.

Com os militares no poder, as reações contrárias ao regime se intensificaram no ano de 1968. Os delitos avalizados pelos atos institucionais, que feriram princípios fundamentais de liberdade e legalidade nos primeiros 
anos de governo dos golpistas, foram a força motriz para a Passeata dos 100 Mil, em junho do mesmo ano. Poucos meses foram necessários para a resposta do governo: o quinto ato institucional, o Al-5, levou o estado de exceção a níveis drásticos e inaugurou o período mais repressivo da ditadura militar.

Nesse momento, em que o regime procurava manter o controle do Estado com mãos de ferro, foram criados os dois principais órgãos de combate à esquerda. O Centro de Operações de Defesa Interna, Codi, e os Destacamentos de Operações de Informações, os DOls. Foram nos porões dos DOI-Codi do Rio de Janeiro e São Paulo que as torturas mais intensas ocorreram. Em 1974, com Ernesto Geisel há a promessa de abertura política. Os anos que se seguem após a transição do regime são de readaptação, balanço de prejuízos históricos, que marcaram a vida de uma geração, e tentativas de reparação dos direitos vilipendiados pela ditadura. Nesse sentido, foi fundamental a promulgação de três leis complementares. Em 1979, a Lei da Anistia foi o primeiro passo para o processo de redemocratização. Em síntese, suspendia as punições de crimes políticos estabelecido pelos atos institucionais anteriores, restaurava a legalidade dos partidos da esquerda e possibilitava o retorno às atividades de "suspeitos" afastados de seus postos e o regresso dos exilados à pátria.

A lei, no entanto, acabou por beneficiar mais os repressores do que os perseguidos pelo regime e não previa qualquer segurança quanto à verdade dos fatos ocorridos nos porões dos órgãos de repressão. Com o passar dos anos e com o reestabelecimento da democracria, antigos arquivos do DOPS Departamento de Ordem Política e Social - estaduais, ainda que alterados, confirmavam as hipóteses de tortura e execução levantadas por familiares dos desaparecidos. Foi quando, já no governo de Fernando Henrique Cardoso, as falhas na lei foram reconhecidas e iniciaram os trabalhos da recém criada Comissão de Direitos Humanos da Câmara dos Deputados. Era o nascimento da lei $n^{\circ}$ 9.140/95, a Lei dos Mortos e Desaparecidos Políticos. A terceira lei complementar à Lei da Anistia é a 10.559/02, que instituiu a Comissão Nacional de Anistia, responsável pelo recebimento e análise de mais de 60 mil requerimentos.

O mais recente trabalho com vistas a averiguar as faltas cometidas contra os Direitos Humanos no regime de exceção foi a instauração da Comissão Nacional da Verdade, que buscou investigar as circunstâncias de vários crimes do período. O relatório final da investigação, entregue no final do ano de 2014 , somou pouco mais de 4.300 páginas e mostrou-se um trabalho custoso, tendo em vista o fato de vários ex-agentes da repressão já estarem mortos, a falta de colaboração das Forças Armadas e a falta de método inicial de pesquisa a ser empreendida. 
II.

Essa casa que eu comprei com a tua falta Prova Contrária, Fernando Bonassi

Os órgãos repressores também eram responsáveis pela censura, que, na época, acometia a comunicação e as artes, em geral. A imprensa brasileira, a literatura, o teatro, o cinema e a música eram rigorosamente cerceados pela repressão. Nessa fase, rica de manifestações artísticas, os escritores e compositores precisavam burlar os censores. Optou-se por elipses, metáforas e alegorias para o alcance desse objetivo.

A literatura de 1964, como convencionou-se chamar o conjunto das obras que retratavam o regime militar, foi profícua. Ainda que algumas das obras literárias desse período tenham sido lançadas em outros países e veiculadas no Brasil posteriormente, muito se produziu na tentativa de denunciar as atividades da ditadura e criticar o período. A produção literária dessa época costuma dividir a crítica literária entre partidários e dissidentes. Três linhas de força se sobressaem: o romance-reportagem, os romances alegóricos e as obras de tom mais confessional, como os diários e a literatura de testemunho. "A mesma chave mestra político-referencial abre todas as portas" (SÜSSEKIND, 1982, p. 61). Essa foi uma das maneiras de lidar com um silenciamento, ora imposto pela censura na imprensa e nas artes, ora pela impossibilidade de qualquer denúncia. Para Süssekind, entretanto

O sucesso desta literatura político-memorialista se explica, então, em parte pela tentativa dessa geração mais jovem de suprir, via memória alheia, as lacunas do próprio conhecimento histórico; em parte pela necessidade de um outro tipo de leitor purgar culpas suscitadas pelo próprio alheamento ou pelo apoio, mudo ou não, dado ao golpe, servindo-se para tal purgação da leitura atenta e obsessiva de quaisquer relatos de calvários políticos que lhe chegassem às mãos (SÜSSEKIND, 1982, p. 44)

Goste-se ou não, foi a manifestação artística que o tempo permitiu. Com a transição política, parece ter havido um período de esquecimento dos horrores recém cometidos. A Lei de Anistia foi um movimento rumo ao silêncio. Necessária naquele momento para a retomada de uma paz aparente, anistiou torturadores, sem investigar os acontecimentos e foi na contramão da história, em comparação com países vizinhos do Cone Sul, em que a Anistia também serviu para conhecer o passado e passá-lo a limpo. No Brasil, não havia uma compreensão detalhada das práticas do período. Somente no início dos anos 2000, com a revisão da referida lei e a posterior criação da Comissão Nacional da Verdade é que a preocupação com o conhecimento pormenorizado dos fatos acontecidos no regime volta à baila. Essa revisão acontece, 
concomitantemente, na literatura, em que se percebe uma leva de produções que tangenciam fatos históricos traumáticos - não só a ditadura militar brasileira - e tentam compreender seus reflexos nas relações humanas.

A obra de Fernando Bonassi é publicada nesse momento em que se resolve romper o pacto com o silêncio e o desconhecimento. Prova Contrária ${ }^{1}$ é a história de indivíduos massacrados pela ditadura mas que tiveram a oportunidade de ser senhores dos seus destinos, ainda que pagando um preço por isso. Os personagens não levam nomes - estratégia que parece recorrente nos trabalhos do escritor paulistano - e a situação inicial da narrativa apresenta uma mulher entre caixas de mudança, em um apartamento recém comprado. Esse é o ambiente em que transita o par e que encena poucos movimentos. $O$ leitor é apresentado ao apartamento, sua área, suas divisórias e ao tempo da história "[...] um tempo depois de outro tempo. Em camadas. De acordo com o sentido que se dá aos sentidos do tempo" (BONASSI, 2003, p. 13).

O primeiro contato é feito com a mulher, ex-militante de esquerda, que realiza o sonho de possuir sua própria casa. Além dos fantasmas acordados em toda mudança, a cada caixa antiga revirada, a cada memória revisitada mas, propositalmente, esquecida até então, a personagem é confrontada com seu passado de maneira mais brutal. Seu companheiro, também militante, é um desaparecido político e é esse fato que proporciona, pela indenização garantida em lei, a realização de seu sonho. O sumiço do homem, "numa esquina, em 1974" (BONASSI, 2003, p. 20) nunca foi esclarecido, mas seu retorno se dá no exato dia da mudança. Sua reaparição é a prova contrária ao direito de indenização e desencadeia uma gama de sentimentos contraditórios na personagem. Rememoração, justificativas e culpa são alguns dos sentimentos que nascem durante o diálogo do (ex)casal. A obra narra esse encontro, acontecido em um espaço não acolhedor, de trânsito entre o passado e o presente.

O panorama traçado até aqui presta-se a tangenciar a obra de Fernando Bonassi e a contextualizar a obra e o evento histórico que se apresenta como um dos propulsores do conflito que se passa com o casal. O livro é apresentado com uma citação indireta da Lei de Mortos e Desaparecidos Políticos

No dia 4 de dezembro de 1995, o então Presidente da República sancionou a Lei número 9.140, que reconhece como mortas as pessoas desaparecidas em razão de participação, ou acusação de participação, em atividades políticas, no

\footnotetext{
1 Publicada no ano de 2003, pela editora carioca Objetiva, a obra foi adaptada para o cinema em 2011. O resultado foi Hoje, dirigido por Tata Amaral e interpretado por Denise Fraga e César Troncoso, vencedor de seis prêmios na $44^{\circ}$ Festival de Brasília de Cinema Brasileiro, dentre os quais 0 de melhor longa-metragem do ano. Disponível em $<$ http://g1.globo.com/distrito-federal/noticia/2011/10/hoje-vence-o-festival-de-cinema-debrasilia.html> Acesso em 15 jan. 2015.
} 
período de 2 de setembro de 1961 a 15 de agosto de 1979. Desta forma, o Estado brasileiro assume responsabilidade pelas arbitrariedades cometidas por seus agentes durante 0 referido período, bem como prevê indenização financeira aos familiares das vítimas.

PS.: a Lei 9.140 não prevê a investigação das circunstâncias em que ocorreram, nem a identificação dos autores dessas arbitrariedades. (BONASSI, 2003, p. 05, grifos nossos)

Há um mote histórico, um referencial não-ficcional como pontapé para o desenrolar da narrativa. Presume-se, por essa passagem, a existência de personagens que se encaixam nesse quadro ou dialogam com ele: um sujeito desaparecido e outro beneficiado pela indenização estabelecida, conforme sinalizamos em itálico no texto. O autor indica, antes de iniciar a narrativa, justamente, "[...] a presença de, pelo menos, três vozes: a do narrador, a de um homem e a de uma mulher. São os três personagens" (BONASSI, 2003, p. 11).

Fernando Bonassi é autor de mais de 30 obras, entre romances, antologias de contos, minificção e dramaturgia. Sua formação acadêmica em Cinema marca sua obra e Prova Contrária é uma obra representativa desse traço. Assim como não é o único trabalho em que o autor se debruça sobre algum fato histórico: Um céu e o fundo do mar (1999) também revive o regime autoritário refletido em uma relação amorosa; Uma pátria que tenho (2011) é um monólogo de um Pracinha enviado para a Segunda Guerra Mundial, que relembra sua experiência-limite; O incrível menino preso na fotografia, de Histórias Extraordinárias (2005) reflete o passado recente do Brasil, tendo como metáfora de espaço opressor as antigas fotografias tiradas nas escolas no período da ditadura. Além, é claro, de alguns textos minificcionais de Passaporte (2001), que transitam pela histórias de vários países.

III.

Que o presente e o passado se misturam, não há novidade pra mulher Prova Contrária, Fernando Bonassi

Os acontecimentos relacionados à ditadura militar brasileira, não há dúvida, tornaram-se matéria de revisitação de manifestações artísticas em vários períodos. $\mathrm{Na}$ contemporaneidade, o trato com o material histórico na literatura aparta-se de concepções pretensamente realistas, de recriar o passado com objetividade. O romance contemporâneo - e seu subgênero, histórico - , cônscio da incapacidade de qualquer recriação ou representação do passado, se permite ser subjetivo pelo diálogo com outras formas de arte e discurso. Ainda assim, alcança um efeito de real, diferente daquele conectado ao paradigma flaubertiano, mas atrelado a uma ruptura com o legado realista, 
que se dá "[...] pela apropriação do real pelo ficcional de formas diversas, com a escrita literária rasurando a realidade que, no entanto, a incorpora" (RESENDE, 2014, p. 14).

Se o romance histórico tradicional, que pretendia reconstruir o passado a partir de uma situação fictícia, dava ao fato histórico especial rigor e atenção, na contemporaneidade percebe-se um movimento diferente. Os novos romances históricos têm tangenciado este elemento para tratar de rupturas e traumas causadas nos agentes da história. Na recente literatura brasileira, um autor que pode ser citado como exemplo deste tipo de ficcionalização é Bernardo Carvalho, dentre outros.

Uma das primeiras alterações percebidas nesses novos romances é a reconstituição temporal. A antiga linearidade cede lugar a anacronismos, que "[...] interrompem e invertem o tempo cronológico, deslocando presente, passado e futuro" (NUNES, 1988, p. 25). Em Prova Contrária o recurso mais comum é a analepse ${ }^{2}$. Por ser completamente desenvolvida a partir de questões de memória, a narrativa recua no tempo, seja na voz do homem ou na voz da mulher. Ele conta versões para o seu sumiço. Ela, o que fez na sua ausência, desde então. Algumas digressões diluem-se nas falas dos personagens e o espaço reservado ao narrador, por vezes, também é contaminado por descrições mais pormenorizadas, que alongam a narração.

A diferença de escolha temporal é uma das marcas do novo romance histórico em relação ao modelo scottiano. Enquanto no último a ficcionalidade transcorria em um passado longíquo, já afastado do tempo da obra, no primeiro há uma constante presentificação. Na novela de Bonassi é majoritário o modo dramático como foco narrativo ${ }^{3}$. Este constiui-se por uma sequência de cenas desenvolvidas por discurso direto e, mesmo aquelas que não têm seu referente no presente, assim são articuladas: "Estou sentado com um copo de café com leite entre as mãos. O café com leite está frio. Faz tempo. Giro de um lado pra outro entre as palmas das mãos, pois essa é a senha" (BONASSI, 2003, p. 28), afirma o homem ao lembrar de uma cena do passado. Em seu discurso, há uma forte sensação de presentificação das cenas rememoradas. Quando é indagado sobre suas atividades enquanto desaparecido, o personagem usa de evasivas e seu discurso passa a ser condicional "Posso ter arranjado uma

\footnotetext{
2 Conforme Arnaldo Franco Júnior, em "Operadores da Narrativa”, analepses são "recuos no tempo, que permitem a recuperação de fatos passados. Corresponde ao que em linguagem cinematográfica é chamado de flashback, mas é anterior, como técnica narrativa, a esse recurso" (2009, p. 47).

${ }^{3}$ Sobre esse foco narrativo, Franco Junior afirma que "A história é narrada de um ângulo frontal e fixo - o que cria o efeito de estarmos presenciando os fatos no momento em que eles acontecem. É o foco que caracteriza o gênero dramático, o texto de teatro e, de certo modo, o roteiro de cinema e das telenovelas" (2009, p. 43). Percebe-se que a forma da novela, por si só, já propicia sua adaptação para o cinema - esse flerte é uma marca característica da contemporaneidade.
} 
identidade. Posso ter comprado uma. Posso ter roubado, trocado fotografias" (BONASSI, 2003, p. 41).

A questão da temporalidade na narrativa, remete-nos ao texto Narrativa histórica e narrativa ficcional, de Benedito Nunes (1988), que ao analisar a investigação de Santo Agostinho sobre o tempo, afirma que este desdobra-se "[...] no passado - que deixou de ser - no presente - que passa - e no futuro que ainda não existe" (p. 18) e que, por isso, na narrativa aparece como uma entidade triplicada: "o presente do presente, o presente do passado e o presente do futuro" (NUNES, 1988, p. 18), visto que quando se analisa outro tempo, é necessário arrastá-lo para o atual, em que se está situado, para então discorrer sobre ele. Toda menção temporal - que não aquela em que os personagens se encontram - é embargada pelo presente: na linguagem, pela expressão verbal; nas impressões de outrora, que foram contaminadas pela memória; pela subjetividade, na dor da separação, aflorada com o retorno do homem. Assim, as reminiscências dos personagens - referente à tortura, ao desaparecimento, ao direito da indenização, à separação - são arrastadas para o atual plano da ficcionalidade. Todas as instâncias são contaminadas, tornando-se um pouco parte do presente. Esse tempo escamoteado é indicado pelo narrador, na primeira frase da obra: "Situação incial: É esse tempo. Ou perto dele. Um tempo depois de outro tempo. Em camadas. De acordo com o sentido que se dá aos sentidos do tempo" (BONASSI, 2003, p. 13)

A memória, aliada à narração em primeira pessoa, opera na literatura reverberando ambiguidades. É possível dar credibilidade à narração de fatos acontecidos há mais de 20 anos? Esse parece ser um dos questionamentos que o autor imprime à obra. Em uma operação que pode ser levada do particular ao geral, há uma suspeita de que, da mesma forma como o homem conta mais de uma história sobre o seu sumiço, a História - por associação apresenta também mais de uma versão para seus fatos, vez que

[...] a rememoração acontece de forma reconstrutiva, partindo sempre do presente. Dessa forma, necessariamente ocorrem modificações, deformações, deturpações, revalorizações e reiterações daquilo que é lembrado na hora da rememoração. No intervalo de sua latência, as lembranças ficam expostas a um processo de transformação. (UMBACH, 2012, p. 219-220)

Uma questão interessante é colocada no cerne dessas várias versões concedidas pelo homem. Toda a novela é fragmentada e cada um dos excertos é nomeado. O narrador é sempre indicado em itálico e os títulos têm um padrão de repetição. A princípio, o narrador marca espaços e faz descrições. Ora assemelha-se a uma voz onisciente, ora suas indicações assemelham-se às didascálias, do texto dramático. A aproximação com indicações cênicas cresce nos momentos de maior tensão do encontro entre os personagens. Os trechos em que a voz do narrador é majoritária são nomeados por um objeto ou pela situação; Fotografia, Imaginação, Mundo Exterior, Jogral, Memória são 
alguns exemplos. É como se o narrador fosse o operador da câmera do modo dramático e a divisão da obra em curtos capítulos facilita a criação dessa impressão.

As intromissões do narrador, normalmente, são digressões entre as falas dos personagens. O retorno à situação do diálogo entre ambos é sempre retomada pelo título "Continuando". Finalmente, as versões da história do homem repetem-se, enumeradas - de primeira à terceira - e, a princípio, podem parecem ser versões diferentes para o mesmo fato. Isso porque os dois primeiros excertos começam e terminam da mesma forma. Cria-se a impressão de uma cena repetida, que talvez não tenha acontecido de fato. O esquema de repetição faz com que duvidemos sobre qual versão seria a verdadeira, assim como a afirmação de que o personagem faz um movimento ensaiado para principiar sua fala. Primeira e segunda versão do homem começam e terminam da seguinte maneira

O homem procura o sofá. Senta-se. É um movimento ensaiado. Um enunciado. Não é de hoje:

- Estou sentado com um copo de café com leite entre as mãos. $\mathrm{O}$ café com leite está frio. Faz tempo. Giro de um lado para o outro entre as palmas das mãos, pois essa é a senha.

$[\ldots]$

A mulher chora. Para dentro. Uma lágrima por cima da outra até chegar à exaustão do peito. As costelas esmagadas. $O$ pulmão colado. Nada. (BONASSI, 2003, p. 28-30/50-53)

É ao final da obra, quando a terceira versão é apresentada, que podemos encaixar as peças-fragmentos e perceber que as versões se completam, alternadas por assuntos e conversas aleatórias. O sumiço do homem foi uma articulação com os inimigos de então. A primeira situação apresenta sua captura e tortura. A segunda, sua transformação em delator de outros militantes de esquerda. Ao final desta, o homem sinaliza que nessa função "[...] Um dia fizemos um juramento de vida ou morte. Eu, o traidor, o "colaborador", e os outros, os agentes, os inimigos. Juramos todos pelo silêncio de nossas ações e sabedorias e fomos cuidar da vida que nos restava" (BONASSI, 2003, p. 53). No terceiro momento, a certeza se firma quando ambos relembram o dia de seu sumiço e há uma lembrança de que o personagem não olha para trás, no instante em que se despede da mulher.

Essa jogada permite desvelar uma versão crítica, consonante com as características do chamado Novo Romance Histórico. Na obra, os grupos antagonistas no regime militar, direita e esquerda, têm seus papéis oficiais rasurados e tal situação mostra como, de certa maneira, a um dado momento, as bases dos movimentos políticos oposicionistas encontravam-se saturadas por tanto tempo de uma situação limite. Cai por terra a ideia de militares carrascos versus militantes massacrados, e o homem é o que mais colabora para essa nova visão. Derruba a concepção de oposição incansável, alia-se 
aos iminigos para proteger sua pele e borra, assim, os limites entre algoz e vítima, tão patentes ao tratar do regime de exceção. A figura de herói torturado e desaparecido é desmistificada e rasurada. Sobressai seu lado humano, antiherói.

Da mesma forma, em relação à mulher também é possível tecer uma interpretação de ruptura com a ideologia socialista, seguida no passado. $O$ fato de ter comprado um apartamento com a dinheiro da indenização, pode ser indicado como uma rendição ao sentimento de posse e individualismo, aos valores pequeno-burgueses. Isso porque fica clara sua vontade em ter uma casa própria, "[...] morar em um lugar onde a luz não estremece toda vez que liga um eletrodoméstico mais potente, como um ferro elétrico ou uma geladeira" (BONASSI, 2003, p. 15). Esse é um dos motivos pelos quais o regresso do homem a atormenta, porque representa um risco à sua estabilidade. Fica patente o pavor contido em suas lembranças de ter a casa invadida pela repressão ou em lhe faltar condições para pagar o aluguel "Porque a fome se disfarça, mas o abrigo é uma intimidade valiosa” (BONASSI, 2003, p. 22).

O espaço do apartamento é caracterizador do estado psicológico da mulher e diz muito sobre as marcas oriundas dos anos de procura, tateados no escuro da desinformação do período. Sua compra simboliza o definitivo enterro de seu passado. Há uma transição subjetiva entre o momento inicial da narrativa e o aparecimento do antigo companheiro. A princípio, há uma satisfação com a possibilidade de um novo lar, que cede lugar a uma indisposição com a nova situação, vez que a sugestão, com a volta do homem, é de que a mulher só tenha conseguido adquirir o imóvel com o valor de um cadáver: seu antigo amor. Essa é uma das cicatrizes, deixadas pelos "anos de chumbo", reavivadas por seu retorno.

A organização espacial da mudança também bem marcada antes e depois de sua volta, é indicativa da determinação (e posterior desalinho) da protagonista. "Sobre a posição de suas roupas nas gavetas ela chegou a deixar bilhetes para si mesma. "Camisetas", "meias", "calcinhas/sutiãs", "outros". A mulher procura pelas caixas de roupas. Confia nas inscrições" (BONASSI, 2003, p. 15). Percebe-se uma ordem excessiva na arrumação, que pretende ser transposta para a vida pessoal. Encerrar o episódio de perda e luto significa reorganizar e retomar sua vida, encaixotada, em suspenso, por anos. Sua reação com a chegada do homem é anunciada por um riso e uma taça quebrada "[...] A gargalha começa a despregar do rosto da mulher e junta-se aos cacos de vidro do assoalho. A boca aberta. O champagne se perdendo pelo assoalho" (BONASSI, 2003, p. 23) e o ambiente passa a ser descrito em desordem. Um desses índices são as taças que se quebram, os cigarros que acabam, coisas acumuladas e desencontradas no espaço. Com o espectro da ditadura e dos sonhos perdidos, que volta na figura do personagem, a casa aparece como metáfora da desordem psicológica, nascida de uma ditadura que 
deixou tudo fora do lugar. Ainda assim, há o desejo de seguir "[...] como se nada houvesse" (BONASSI, 2003, p. 62).

A visita suscita os restos do período. De memória, guardados em compartilhamentos subjetivos, e físicos, uma mudança desorientada, que dispõe em caixas de papelão as poucas lembranças do passado. Ressuscita, ainda, as suas cicatrizes - físicas, pelas torturas rememoradas sucintamente nos diálogos do antigo casal e psicológicas, já que evocam feridas e separações. Em consonância com uma tendência contemporânea do romance histórico, Prova Contrária não se preocupa em reconstituir o passado, mas sim exumá-lo, para perceber suas implicações e reflexos na atualidade.

\title{
PROVA CONTRÁRIA: REMAINS AND SCARS
}

\begin{abstract}
The period of the Brazilian military dictatorship was one of the darkest in our official history. This article intends to analyze the work Prova Contrária, of the author from São Paulo, Fernando Bonassi, published in 2003, that thematizes, in some way, such historical episode. The intention is to understand how the literary treatment is used in revisiting the fact. To this end, we will present some theoretical questions about the contemporary historical novel and a panorama about the post-64 literature will be traced in order to understand the work of Fernando Bonassi inserted from the prerogatives that underpin this subgenre and how it signals a subjective set of remains and scars of the "lead years."
\end{abstract}

Keywords: contemporary brazilian literature; military dictatorship; Fernando Bonassi.

\section{REFERÊNCIAS}

BONASSI, Fernando. Prova Contrária. Rio de Janeiro: Objetiva, 2003.

FRANCO JR., Arnaldo. Operadores de leitura narrativa. In: BONNICI, Thomas; ZOLIN, Lúcia Osana (Orgs.). Teoria Literária: abordagens históricas e tendências. Maringá: Eduem, 2009.

MÜLLER, Heiner. Quatro textos para teatro: Mauser, Hamlet-máquina, A missão, Quarteto. Trad. de Reinaldo Mestrinel. São Paulo: Editora Huciter, 1987.

NUNES, Benedito. Narrativa histórica e narrativa ficcional. In: RIEDEL, Dirce C. (Org.). Narrativa: ficção e história. Rio de Janeiro: Imago, 1988.

RESENDE, Beatriz; FINAZZI-AGRÓ, Ettore (orgs.). Possibilidades da nova 
escrita literária no Brasil. Rio de Janeiro: Revan, 2014.

SÜSSEKIND, Flora. Retratos \& Egos. In: Literatura e vida literária: polêmicas, diários e retratos. Rio de Janeiro: Jorge Zahar, 1982.

UMBACH, Rosani Ketzer. Violência, memórias da repressão e escrita. In: SELLIGMANN-SILVA, Márcio; GINZBURG, Jaime; HARDMAN, Francisco Foot (Orgs.). Escritas da violência, vol. 1: o testemunho. Rio de Janeiro: 7letras, 2012. 